\title{
O quimbundo e o português do Libolo (Angola): línguas em contato
}

Paulo Jeferson Pilar Araújo ${ }^{a}$

Margarida Petter ${ }^{b}$

\section{Resumo}

A subvariedade de português falada em Angola, no município do Libolo, província do Kwanza Sul, é segunda língua para uma boa parcela da população desse município. Este artigo apresenta resultados decorrentes de investigações no âmbito de um projeto interinstitucional e internacional: o Projeto Libolo, focalizando especificamente o contato do quimbundo na sua variedade conhecida como ngoya ou kibala (H23) com o português do Libolo. Para tratamento dos dados, utilizam-se os modelos teóricos desenvolvidos por Myers-Scotton (2002) e Myers-Scotton e Jake (2016), notadamente o modelo dos 4-M como forma de verificar as preferências lexicais nos fenômenos de codeswitching e empréstimo entre as duas linguas em foco. São apresentados dados preliminares do corpus do quimbundo examinados sob o prisma dos modelos teóricos em pauta neste trabalho. Busca-se ainda compreender como o português e o quimbundo estão relacionando-se como línguas em contato e como essa relação pode contribuir para as discussões sobre um continuum afro-brasileiro de português (PETTER, 2008).

Palavras-chave: Quimbundo. Português.

Linguas em contato. Libolo.

Recebido em: 30/09/2020 Aceito em: 19/11/2020

\footnotetext{
a Universidade Federal de Roraima, Programa de Pós-Graduação em Letras. E-mail: paulo.pilar@ufrr.br

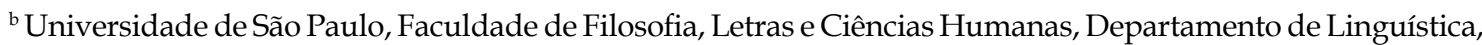
Programa de Pós-Graduação em Linguística, E-mail: mmtpetter@uol.com.br
}

\section{Como citar:}

Araújo, P. J. P.; Petter, M. O quimbundo e o português do Libolo (Angola): línguas em contato. 


\section{Introdução}

A influência de línguas africanas em variedades do português é tema bastante comum e apontado em análises, geralmente substratistas, como principal fator na configuração dessas variedades, promovendo a ideia de um continuum de português na África lusófona e no Brasil (LÓPEZ; GONÇALVES; AVELAR, 2018). Neste trabalho, tomamos a via inversa ao apresentarmos dados de uma subvariedade do quimbundo, língua africana do grupo banto, falada no Libolo, e alguns aspectos dos contatos linguísticos também com uma subvariedade de português do interior de Angola.

O objetivo deste artigo é apresentar dados do quimbundo que corroborem a situação de contato entre essa língua banta com a variedade de português angolano. Uma discussão teórica pautada nos modelos de Myers-Scotton (2002) e Myers-Scotton e Jake (2016) é realizada com base nos dados analisados. Os dados de empréstimos e codeswitching se restringem à estrutura de nomes e verbos da língua banta, além de marcadores discursivos por serem considerados morfemas de conteúdo no modelo teórico selecionado. Pretende-se que, além de apresentar dados primários de contato linguístico do quimbundo com o português, os modelos teóricos ora utilizados sejam empiricamente mais informados.

Oartigo está organizado em quatro seções principais, além desta introdutória e das considerações finais. Primeiramente, trazemos informações sobre as línguas do estudo no âmbito do projeto que deu suporte ao trabalho de campo em 2013. Apresentamos ainda, em uma subseção, a metodologia seguida no tratamento dos dados. Na sequência, por fim, os dados são apresentados e os exemplos são analisados com base numa discussão teórica dos modelos em pauta, particularmente do modelo dos 4-M.

\section{O Projeto Libolo e os trabalhos sobre as variedades do português e quimbundo}

${ }^{1}$ Por questões de espaço, direcionamos os leitores ao trabalho de Figueiredo (2019) para uma abordagem histórica e cultural do Libolo.

\section{O Projeto Libolo e a metodologia seguida}

Em 2013, uma equipe internacional de pesquisadores realizou uma viagem de campo para a região do Kwanza Sul, município do Libolo ${ }^{1}$, para a coleta de dados e pesquisa 
${ }^{2} \mathrm{O}$ projeto Município do Libolo, Kwanza Sul, Angola: aspectos linguístico-educacionais, histórico culturais, antropológicos e sócioidentitários, também conhecido como Projeto Libolo, é parcialmente financiado pela

Universidade de

Macau e por entidades privadas filantrópicas de Angola. Tratase de um projeto internacional e multidisciplinar cujos pesquisadores intervêm, de forma articulada, em pesquisas nas áreas de Linguística,

História, Antropologia, Etnografia, Filologia e Ações Pedagógicas. O Projeto Libolo é também membro da Cátedra UNESCO em

Políticas Públicas para

o Multillinguismo e está devidamente patenteado pelo Centro de Investigação e Desenvolvimento (R\&DAO) da

Universidade de Macau, sob o número de referência SRG011-FSH13-CGF, encontrando-se, desta forma, ao abrigo da vigente proteção de direitos autorais de propriedade intelectual designada por "Copyright (C) 2016, R\&DAO University of Macau.

${ }^{3}$ Uma boa parte dos trabalhos produzidos sobre o português do Libolo podem ser acessados pelo site Cátedra do Português (c.2008). exploratória. Nasceu assim o Projeto Libolo ${ }^{2}$ que atualmente se encontra em uma segunda fase de pesquisas. Naquela ocasião, os pesquisadores se organizaram em diferentes equipes disciplinares: equipe do português L1 e L2, do quimbundo, equipe da educação, equipe da antropologia e equipe da história. As quatro comunas do município foram visitadas. O material coletado compõe uma grande base de dados que está sendo organizada e transcrita para descrição e análise. Os resultados preliminares dessa primeira viagem de campo foram coligidos em publicação de dois volumes (FIGUEIREDO; OLIVEIRA, 2016; FIGUEIREDO, 2016).

Os dados utilizados neste trabalho são provenientes dessa primeira viagem de campo exploratória. Os exemplos foram transcritos com o auxílio de um falante nativo do quimbundo, colaborador de pesquisa. Foram selecionados do corpus preliminar os excertos contendo exemplos de codeswitching e empréstimos. Vale ressaltar que a metodologia utilizada no manuseio desses dados não seguiu as atuais diretrizes que as equipes de linguística do português L1 e L2 do Libolo seguem atualmente, já que, naquele momento, ainda não havia sido decidido qual software de transcrição seria usado na transcrição dos dados do quimbundo. Inicialmente foi considerado o ELAN por sugestão de membros da equipe de linguística do quimbundo, e parte dos exemplos aqui apresentados foram transcritos nesse programa.

\section{As variedades de português e quimbundo do Libolo}

Até o momento, os trabalhos do Projeto Libolo têm se concentrado sobre a variedade de português do Libolo ${ }^{3}$, recorrendo aos dados do quimbundo para explicar a configuração de certos aspectos da gramática (FIGUEIREDO; OLIVEIRA, 2016; 2013; FIGUEIREDO, 2019). Quanto ao quimbundo, os trabalhos têm sido transversais, não abordando diretamente a língua africana. O conhecimento do quimbundo do Libolo pode trazer luz à dialetologia das línguas bantas de Angola, além de contribuir com os trabalhos sobre o português de Angola e as interferências recebidas do quimbundo. Os trabalhos de Angenot, Mfuwa e Ribeiro (2011) e Angenot, Angenot e Huta-Mukana (2013) já apontavam para a variedade do quimbundo do Libolo denominado pelos seus falantes 
${ }^{4}$ A tradição bantuista, desde o sistema de classificação de Greenberg para as línguas bantas, é baseada em áreas geográficas sinalizadas por uma letra do alfabeto seguida de uma numeração. Por exemplo, o grupo quimbundo é H20 enquanto o do quicongo é H10. Em Angola existem os grupos $\mathrm{H}, \mathrm{K}$ e R.
${ }^{5}$ Seguimos aqui a sugestão de Petter (2015) para o aportuguesamento dos nomes de línguas africanas. como ngoya. Essas duas publicações ensejaram a inclusão dessa variedade de quimbundo no inventário de línguas bantas (HAMMARSTRÖM, 2019) da segunda edição do The Bantu Languages (VELDE et al., 2019), recebendo a classificação H23 (HAMMARSTRÖM, 2019, p. 39) do grupo quimbundo H204.

A região do Libolo pode ser considerada multilíngue por ser uma zona de transição entre dois grupos etnolinguísticos, dos falantes de quimbundo (H20) e umbundo (R10), além do português, considerada uma língua franca para os diversos grupos étnicos de Angola. A situação sociolinguística do Libolo parece ser a de convergência e atrito de línguas, nos termos de Myers-Scotton (2002), constatação que precisa de dados mais seguros para uma melhor formulação desses processos. Foi observado na primeira viagem de campo exploratória que na sede do município do Libolo, Calulo, o português é dominante, tendo já substituído o quimbundo como L1 de muitos falantes. Já nas demais comunas administrativas ou distritos, Munenga, Cabuta e Quissongo, o quimbundo é falado preferencialmente.

De qualquer modo, a língua africana tem alta vitalidade, apesar de a política linguística angolana não oferecer a devida atenção às suas línguas nacionais, a exemplo de outros países lusófonos na África.

\section{Línguas bantas e modelos teóricos de línguas em contato}

\section{As línguas bantas e seus contatos}

Mous (2019) oferece um panorama dos estudos sobre contato linguístico no domínio banto. $\mathrm{O}$ autor adverte que seu texto complementa o de Mufwene (2003) na primeira edição do The Bantu Languages, ao apresentar, além das línguas de contato conhecidas na área banta, como o lingala e o quituba ${ }^{5}$, os processos de mudança induzidos pelo contato, da fonologia à sintaxe. Mous se detém muito mais na questão dos empréstimos de tons, nas classes nominais e nos verbos, mas enfatiza o contato entre línguas bantas. Alguns dados sobre contato entre línguas bantas e não bantas são mencionados.

Neste artigo, detemo-nos principalmente no nome e no verbo em exemplos de codeswitching e empréstimos como forma de iniciarmos uma discussão sobre os modelos teóricos a ser apresentados e os dados de contato. Para isso, expomos 
${ }^{6}$ Foram produzidos até o momento sete manuais de alfabetização, além do quimbundo, para as línguas umbundo, quicongo, chokwê... Os manuais podem ser baixados de alguns sites como o do IdentidÁfrica (c.2010). brevemente as particularidades da estrutura nominal e verbal das línguas bantas para uma melhor discussão sobre os processos de contato entre as línguas deste trabalho. Não serão anotados os tons, de modo que os exemplos em quimbundo buscam seguir na medida do possível o registro ortográfico proposto para as línguas de Angola em manuais de alfabetização (ARSÉRNIO; SEBASTIÃO; ADÃO, 2012)

Para o quimbundo, Huth (1984), Pedro (1993) e Xavier (2010) concordam sobre a existência de 18 classes nominais e nove gêneros pautados na oposição singular/plural dos nomes, sendo as classes de 1 a 15 as que formam os nove gêneros e as classes 16, 17 e 18 as três classes nominais locativas, que expomos no quadro a seguir:

Quadro 1 - Gêneros e classes nominais do quimbundo

\begin{tabular}{|c|c|c|c|c|}
\hline Gêneros & $\begin{array}{l}\text { Classes/ } \\
\text { Prefixos }\end{array}$ & $\begin{array}{l}\text { Valores aproximados } \\
\text { (semânticos) }\end{array}$ & \multicolumn{2}{|c|}{ Exemplos } \\
\hline I & $\begin{array}{l}1 \text { mù- } \\
2 \text { à- }\end{array}$ & Humanos & $\begin{array}{l}\text { mù-tù } \\
\text { à-tù }\end{array}$ & $\begin{array}{l}\text { pessoa } \\
\text { pessoas }\end{array}$ \\
\hline II & $\begin{array}{ll}3 & \text { mù- } \\
4 & \text { mì- }\end{array}$ & Plantas e objetos & $\begin{array}{l}\text { mù-xì } \\
\text { mì-xì }\end{array}$ & $\begin{array}{l}\text { 'árvore' } \\
\text { 'árvores' }\end{array}$ \\
\hline III & $\begin{array}{ll}5 & \text { lì- } \\
6 & \text { mà- }\end{array}$ & $\begin{array}{c}\text { Plantas, objetos, partes do } \\
\text { corpo, } \\
\text { coletivo, líquidos }\end{array}$ & $\begin{array}{l}\text { dì-zwì } \\
\text { mà-zwì }\end{array}$ & $\begin{array}{l}\text { ‘língua' } \\
\text { 'línguas' }\end{array}$ \\
\hline IV & $\begin{array}{ll}7 & \text { kì- } \\
8 & \text { ì- }\end{array}$ & $\begin{array}{l}\text { Objetos fabricados, seres } \\
\text { geralmente } \\
\text { inanimados }\end{array}$ & $\begin{array}{l}\text { k-ìnù } \\
\text { ìnù }\end{array}$ & $\begin{array}{l}\text { 'pilão' } \\
\text { 'pilões' }\end{array}$ \\
\hline V & $\begin{array}{l}9 \text { Ø/í- } \\
10 \text { jì- }\end{array}$ & $\begin{array}{c}\text { Animais, fenômenos } \\
\text { naturais }\end{array}$ & $\begin{array}{l}\text { hòmbò } \\
\text { jì-hòmbò }\end{array}$ & $\begin{array}{l}\text { 'cabra' } \\
\text { 'cabras' }\end{array}$ \\
\hline VI & $\begin{array}{l}11 \text { lù- } \\
6 \text { mà- }\end{array}$ & Objetos & lù-mbù & "parede' \\
\hline VII & $\begin{array}{l}12 \text { kà- } \\
13 \text { tù- }\end{array}$ & Diminutivo & $\begin{array}{l}\text { kà-mbwa } \\
\text { tù-mbwa }\end{array}$ & $\begin{array}{r}\text { 'cachorrinho' } \\
\text { 'cachorrinhos' }\end{array}$ \\
\hline VIII & $\begin{array}{l}14 \text { ù- } \\
6 \text { mà- }\end{array}$ & Abstratos, maneiras & ù-kàmbà & 'amizade' \\
\hline IX & $\begin{array}{l}15 \text { kú- } \\
6 \text { mà- }\end{array}$ & Infinitivo & kù-yà & 'ir' \\
\hline & $\begin{array}{l}16 \text { bù- } \\
17 \text { kù- } \\
18 \text { mù- }\end{array}$ & $\begin{array}{l}\text { Localização precisa } \\
\text { Proximidade } \\
\text { Interioridade }\end{array}$ & $\begin{array}{l}\text { bù-lù } \\
\text { kù-kù } \\
\text { mù-bàtá }\end{array}$ & $\begin{array}{l}\text { 'no céu' } \\
\text { 'aqui' } \\
\text { 'na casa' }\end{array}$ \\
\hline
\end{tabular}

Fonte: Elaboração própria (Adaptado de PEDRO, 1993, p. 138 e XAVIER, 2010, p. 177) 
Como exemplo do sistema de classes nominais das línguas bantas, apresentamos o seguinte:

(1) Quimbundo (H21) (Adaptado de Xavier, 2010, p. 118)

$\begin{array}{lcccc}\text { lì-álà } & \text { lì-á-mí } & \text { lí-áfíkì } & \text { nì } & \text { lì-ákínì } \\ \text { 5-homem } & \text { 5-de-mim } & \text { 5-cantou } & \text { e } & \text { 5-dançou } \\ \text { 'meu marido cantou e dançou' } & & \end{array}$

Em (2), é apresentado exemplo para o plural na classe 6, indicando a concordância desencadeada pelo sistema nominal:

(2) Quimbundo (H21) (Xavier, 2010, p. 118)

$\begin{array}{lllll}m a ́ \text {-lá } & m a ̀ \text {-á-mbánzá } & \text { má-jíkì } & \text { nì } & m a ̀ \text {-ákínì } \\ \text { 6-homem } & \text { 6-da-cidade } & \text { 6-cantou } & \text { e } & \text { 6-dançou }\end{array}$

'os homens da cidade cantaram e dançaram'

Mous (2019, p. 365) aponta que, em situação de contato entre duas línguas bantas, a atribuição de gênero ocorre em três situações: (i) a primeira sílaba é reanalisada como prefixo de classe, a exemplo do empréstimo ka-valu, identificado em várias línguas bantas em que a sílaba inicial de 'cavalo' é entendida como prefixo; (ii) a acomodação das palavras numa mesma classe nominal por relação semântica; e (iii) o nome é inserido em uma classe nominal com alomorfe zero.

O verbo nas línguas bantas apresenta uma estrutura que os bantuístas denominam 'palavra verbal' por integrar ao verbo um conjunto de afixos que carregam as informações de uma sentença inteira, como marca de sujeito, marca de objeto, tempo, modo e aspecto etc., e um número de extensões verbais que podem mudar a valência dos verbos, como aplicativos, causativos, passivas, entre outras, conforme esquema seguinte: 
(3) Estrutura do verbo banto (Adaptado de ARAÚJO; PETTER; JOSÉ, 2019, p. 22)

$$
\text { (PI) - IS - MT + (MO) + Raiz + (Exts. })+ \text { VF: }
$$

PI = pré-inicial (marca de negação, nas línguas que o possuem);

IS = índice do sujeito;

$\mathrm{MT}=$ marca de tempo;

$\mathrm{MO}$ = marca de objeto, único morfema que tem posição fixa, sempre antes da raiz;

Exts. $=$ extensões verbais, que são morfemas derivacionais modificadores do sentido e da morfologia do radical verbal, podendo, também, alterar as relações de transitividade;

$\mathrm{VF}=$ vogal final, podendo indicar aspecto.

No esquema referido os elementos entre parênteses não são obrigatórios. Um exemplo do quimbundo pode ilustrar melhor:

Quimbundo (Pedro, 1993, p. 272)
Ng-á-jik-úl-á
MS-MT-abrir-EXT-VF
'Eu abri a porta'

Quanto aos empréstimos de verbos na estrutura do verbo banto, Mous (2019, p. 370-2) atesta que cada língua utiliza diferentes estratégias e geralmente a raiz verbal ocupa a mesma posição no verbo banto, sendo acrescida dos afixos próprios da língua. Os fenômenos de contato para as línguas bantas discutidos por Mous (2019) ensejam um tratamento teórico condizente com a estrutura das línguas bantas, tema da próxima subseção. 
${ }^{7}$ Para uma apreciação sobre o modelo de Coetsem (2000), na impossibilidade de nos determos sobre ele aqui, sugerimos a leitura de Winford (2013).

${ }^{8}$ Petter (2008) prefere traduzir o Matrix Language Frame model apenas como 'modelo de Língua Matriz'.

\section{Breve apresentação dos modelos teóricos da Myers-Scotton}

Beyer (2020, p. 863-4) sugere as propostas de Matras (2009) para o tratamento das situações de contato para as línguas africanas, partindo da premissa de que o ideal para esses fenômenos seja um modelo teórico universalista que possa dar conta dos diversos contextos de contato, independente da configuração tipológica das línguas. Desde o trabalho de Coetsem (2000) e seu modelo universalista ${ }^{7}$, outras propostas têm surgido sob diferentes prismas metodológicos e epistemológicos. Desses modelos, os de Myers-Scotton (2002) chamam a atenção por algumas características. Uma delas é a preocupação de ser um modelo pautado em uma base psicolinguística, de processamento linguístico, o modelo thinking for speaking de Levelt (1989). Além desse, é interessante perceber a elaboração dos modelos de Myers-Scotton se iniciou a partir de dados de línguas bantas, como o suaíli. Essa familiaridade com o uso de dados de línguas bantas tornam os modelos da autora chamativos para um mesmo tratamento com os dados do quimbundo já que as línguas bantas compartilham amplamente de traços tipológicos.

Uma outra motivação é que considerando os modelos de Myers-Scotton, Petter (2008) delineou inicialmente sua proposta de um continuum afro-brasileiro de português, servindo como mote para trabalhos posteriores sobre a relação entre línguas africanas, notadamente bantas, e o português no Brasil e na África lusófona (LÓPEZ; GONÇALVES; AVELAR, 2018).

A ideia principal da proposta de Myers-Scotton (2002) é a de Língua Matriz ou o modelo do Enquadramento da Língua Matriz $^{8}$ (Matrix Language Frame model) em relação a uma Língua Encaixada (Embedded Language). Inicialmente, como suporte desse paradigma, a autora propunha o modelo dos 4-M e o de Nível Abstrato. Este entendido antes como um molde que dava suporte ao do Enquadramento da Língua Matriz, o modelo dos 4-M servia de certo modo para identificar a Língua Matriz (LM) por ser essa a língua que contribui com o aspecto morfossintático nos fenômenos de contato, enquanto a Língua Encaixada (LE) contribui com o léxico, ou seja, os morfemas de conteúdo. 
A classificação de morfemas dentro do modelo de 4-M tem recebido algumas críticas no que diz respeito à identificação dos tipos de morfemas, considerando que tal classificação pode variar de língua para língua. Por exemplo, a divisão feita entre morfemas no modelo dos 4-M não pode ser confundida com aqueles comumente considerados como lexicais e gramaticais. Há palavras funcionais que, no modelo dos 4-M, são consideradas de conteúdo, por exemplo. O modelo de 4-M toma como oposição básica a forma como os sistemas de morfemas são acessados no nível do léxico mental [+/- conceptualmente ativado]. Com essa oposição, tem-se uma subdivisão de morfemas em acordo com as necessidades e intenções comunicativas do falante. Os morfemas são subdivididos em:

- Morfemas [+ conceptualmente ativados], subdivididos em dois tipos: os "morfemas de conteúdo" (content morphemes): geralmente nomes e verbos; e os "morfemas gramaticais precoces" (early system morphemes), geralmente morfemas que acompanham um núcleo como determinantes e artigos;

- Morfemas [- conceptualmente ativados], também subdivididos em dois: os morfemas gramaticais tardios pontes" (bridge late system morphemes), aqueles que são indiretamente acessados e satisfazem a organização de constituintes maiores como a preposição de, utilizada em uma relação possessiva (o livro de Paulo); e os "morfemas gramaticais tardios exteriores" (outsider late system morphemes), geralmente aqueles que satisfazem relações fora do núcleo adjacente, como exemplo, as marcas de concordância entre sujeito e predicado como também as relações de tempo, aspecto e modo ou marcas de caso, em línguas que apresentam tais categorias casuais.

O Modelo dos 4-M tem recebido críticas pela não equivalência entre tipos de morfemas nesse modelo entre línguas tipologicamente diferentes (por exemplo, as preposições locativas em português e as classes nominais locativas do quimbundo encaradas como de mesma categoria gramatical pela sua semântica locativa). Para dar conta de diversas situações em que seu modelo dos 4-M não satisfaz 
perfeitamente, Myers-Scotton tem refinado o modelo do Nível Abstrato, o qual prevê a atuação de um construto teórico que reforçaria a necessidade da assimetria entre as línguas em uma relação de contato. O modelo dos 4-M seria mais adequado para os casos de codeswitching clássico, como já mencionado. Mais recentemente, Myers-Scotton e Jake (2016) revisitam o modelo 4-M propondo uma Hipótese da Escolha Variável (Variable Election Hypothesis) que auxiliaria a identificar melhor, a partir do Nível Abstrato, a hierarquia em que os diferentes tipos de morfemas são eleitos para figurar em uma sentença de contato, permitindo que o modelo dos 4-M possa ser útil também para outras situações de contato, como empréstimos e formação de línguas crioulas.

Para deixar mais ilustrativo, vejamos um exemplo de codeswitching entre o suaíli e o inglês e a análise possível no uso do modelo dos 4-M:

(5) Codeswitching suaíli-inglês (MYERS-SCOTTON; JAKE, 2016, p. 352)

A friend of mine a-li-ni-buy-i-a simu

Um amigo meu 3s-PASS-IS-comprar-APL-VF celular

'Um amigo meu comprou um celular para mim'

Nesse exemplo, observamos nomes e verbo do inglês na estrutura do suaíli: a friend of mine ocupando todo um sintagma, enquanto o verbo buy é inserido dentro da estrutura do verbo banto. Do suaíli, que exerce o papel de Língua Matriz (LM) no enunciado, a estrutura morfossintática e os morfemas mais gramaticais como marca do sujeito, marca do objeto, sistema TAM e valência provêm da língua africana. Os nomes e verbos são morfemas de conteúdo, e morfemas que acompanham o núcleo são morfemas gramaticais precoces, a exemplo de of (de) na posse atributiva. As marcas de concordância e demais informações morfossintáticas, como o índice do sujeito, o tempo e o aplicativo, podem ser morfemas gramaticais ponte. A concordância e outras informações de nível mais abstrato, como caso, são decorrentes dos morfemas gramaticais tardios exteriores. Pelo modelo da autora, esses últimos morfemas seriam os que mais resistem à transferência em situações de contato. 
Apresentadas as estruturas do nome e do verbo banto e o suporte teórico em vista, apresentamos nas subseções seguintes os exemplos retirados do corpus que demonstram como o português e o quimbundo se comportam como línguas em contato.

\section{O quimbundo em contato com o português no Libolo}

Apresentamos aqui alguns aspectos do contato do quimbundo com o português do Libolo. Vamo-nos deter principalmente na acomodação de empréstimos na estrutura nominal e verbal da língua banta, além dos marcadores discursivos, para, em seguida, abordarmos esses dados à luz do modelo dos 4-M de Myers-Scotton (2002) e Myers-Scotton e Jake (2016).

\section{Nomes e marcas de classes nominais}

Antes de discutir os dados a seguir, vale mencionar a dificuldade em identificar seguramente os casos de codeswitching e empréstimo nos exemplos do quimbundo em razão do conhecimento dos empréstimos já nativizados na língua. Alguns exemplos são os casos de empréstimos de preposições e conjunções já atestados no quimbundo desde as gramáticas produzidas por religiosos, a exemplo de maji (mas) (MAIA, 1951, p. 114), e as preposições pala (para) (CHATELAIN, 1988/89, p. 6) e katé (até) (MAIA, 1964, p. 74 e 102) e a condicional se (da mesma forma que no português) (CHATELAIN, 1988/89, p. 49).

Apresentamos, assim, algumas ocorrências já atestadas na literatura e outras que poderão colaborar em análises futuras, para uma melhor delimitação entre os fenômenos de empréstimo e codeswitching quimbundo-português.

No exemplo em (6), a seguir, temos a ocorrência de marcador discursivo e de morfemas do português, na fala em quimbundo de uma informante que corrige o intérprete que tinha pronunciado a palavra mundwe como muntwue, que ela esclarece ser a tradução em quimbundo para na tchabeça: 
(6)

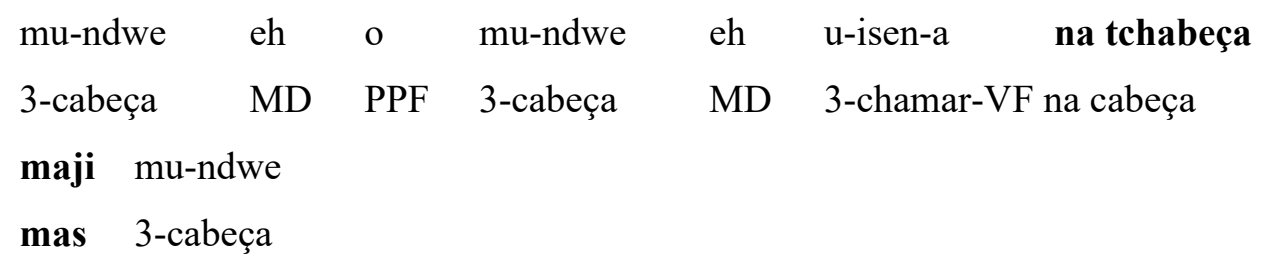

'Na cabeça (que se diz), é... a cabeça, é... chama-se cabeça, mas "mundwe" (e não mutwe)'

Myers-Scotton aponta a produtividade da classe 9 para nomes estrangeiros; no caso do quimbundo, as palavras para português, nputu, e igreja, ngeleja, aparecem com o N-comum para a classe 9 em muitas outras línguas do grupo banto. No entanto, para o quimbundo, a marca é $\varnothing$ ou i-, conforrme já indicado no quadro 1 e conforme a terceira estratégia atestada por Mous (2019, p. 365), em que as línguas bantas acomodam seus empréstimos em classes nominais com alomorfe zero. A nasal que precede essas consoantes não é um morfema de classe, trata-se de uma pré-nasalização da consoante $\mathrm{p}$, em $n p t u$ e o fonema /ng/ do quimbundo, que é sempre pré-nasalizado, pois não ocorre a contrapartida oral $[\mathrm{g}]$. Todos os empréstimos do português com esse som são realizados como /ng/, como ngalasa (graça), etc.:

(7)

\begin{tabular}{|c|c|c|c|c|}
\hline eme & ka-nhi-en-e & $\mathrm{mu}$ & & ngeleja eme \\
\hline $1 \mathrm{ps}$ & NEG-costumar(ir)-VF & LOC & & igreja \\
\hline \multicolumn{2}{|c|}{ ka-nhi-a-ij-il-e } & nputu & só & ki-mbundu \\
\hline NEG & -conhecer-PF-VF & português & só & 7-quimbundo \\
\hline
\end{tabular}

'Eu não tenho o costume de ir à igreja, eu não conhecia português, só quimbundo.

Pela semântica da palavra 'português' seria esperado que o prefixo ki-, classe 7, fosse utilizado para os nomes que indicam línguas, a exemplo do ki-mbundu, ki-kongo etc. Nesse mesmo exemplo, em (7), vemos o uso de 'só', advérbio do português no quimbundo. Esse termo ainda não foi atestado nas transcrições, já que existe um outro equivalente em quimbundo que é utilizada em outros momentos, mas, nesse exemplo, o falante deu preferência ao uso do advérbio em português configurando 
assim um exemplo de codeswitching. Pela classificação do modelo dos 4-M, o advérbio 'só' poderia ser encarado como um morfema gramatical precoce, pairando dúvida, no entanto, sobre o seu estatuto como morfema gramatical tardio ponte.

No corpus preliminar, alguns casos de codeswitching e/ou empréstimos são atestados sem que os nomes sejam integrados aparentemente a uma das classes nominais do quimbundo. Por exemplo, há ocorrências da palavra avó sem marcas de classe nominal. Em outras ocasiões, os informantes utilizam a palavra em quimbundo kuku para avós, e, em outros momentos, é a palavra vwelo para 'velho', conforme os exemplos que seguem:

(8) Codeswitching quimbundo-português ${ }^{9}$
avó, kuji u-anda-tand-a
m-o-m-o ${ }^{10} \quad \mathrm{ku}$
ma-nano
avó como MS-querer-contar-VF
lá
17 6-provérbios

'Avó, como é, vai contar lá os provérbios?'

\footnotetext{
${ }^{9}$ Neste exemplo, o verbo kuanda (querer) é usado como marca de futuro.

${ }^{10}$ Verifica-se repetição por hesitação na fala do informante para a classe $18 \mathrm{mu}$.
}

Nos próximos dois exemplos, os informantes utilizam novamente uma palavra do português em substituição ao que seria esperado em quimbundo, kota, em referência aos mais velhos, além de usar o nome conda (para conta), havendo apenas a adequação fonológica na língua banta:

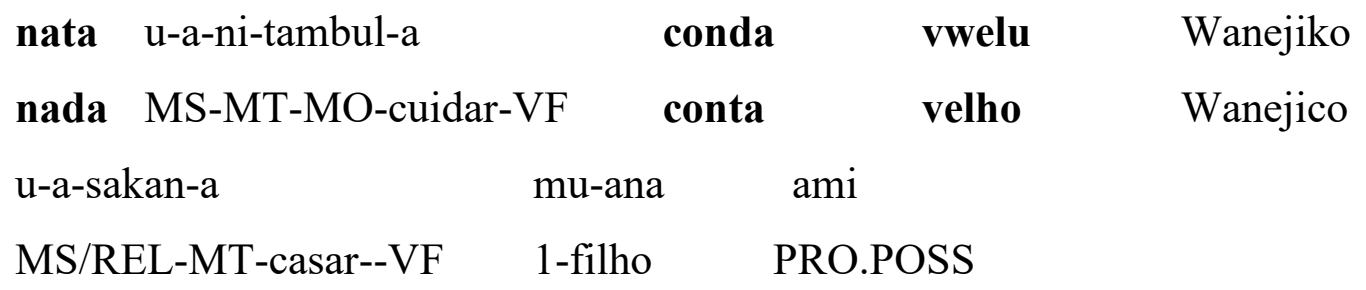

'Nada! Toma-me conta o velho Wanéjico, (que) casou com minha filha.'

A palavra conda (conta) entra como morfema de conteúdo referente à marca de objeto dando o sentido de 'tomar conta'. Vale verificar se realmente seria necessário esse morfema de conteúdo nesse exemplo e se apenas o verbo tambula (cuidar) supriria a estrutura argumental desejada pelo falante bilíngue. 
Nesse exemplo, já aparece o nata (nada) a ser discutido sobre os marcadores discursivos.

\section{O verbo banto do quimbundo e acomodação de empréstimos do português}

Sempre que um verbo for emprestado por uma língua banta, é ele inserido na palavra verbal, recebendo todas as marcas e extensões que um verbo normalmente recebe nas línguas bantas. A seguir, o caso dos verbos kulembala (lembrar) e acontecela (acontecer):

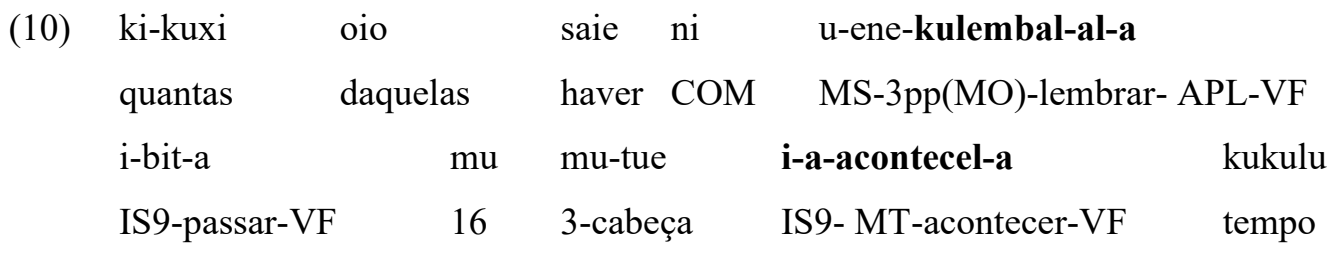

'Quantas daquelas, daquelas (anedotas), há em... estás a lembrar para eles, passam pela cabeça, que tinham acontecido antigamente?'

Neste exemplo, à semelhança com aquele do suaíli no exemplo (5) do codeswitching suaíli-inglês, observa-se que apenas a raiz verbal do português é preservada com as adequações fonológicas da língua africana. A morfologia verbal, no entanto, com todas as marcas de flexão e extensões verbais, são do verbo banto. No caso de kulembalala, verifica-se uma ocorrência única em que o falante acrescentou a marca do infinitivo em quimbundo, com o prefixo ku-, da classe 15. Em todos os demais dados, o verbo do português não recebe a marca do infinitivo.

\section{Marcadores discursivos}

O interesse pelo caráter dos marcadores discursivos em quimbundo e português decorreu de questionamentos sobre o real estatuto dessas palavras no modelo dos 4-M. Para Myers-Scotton (2002), os marcadores discursivos (MD) são morfemas de conteúdo. Indagamos se esse seria o caso para todos os exemplos do quimbundo. Para isso, trazemos para a discussão alguns exemplos para posterior discussão. Não foi detectado, no atual estágio de investigação, o uso de MDs do quimbundo no português, por outro lado, os MDs do 
português em quimbundo estão bem presentes, a exemplo de "então", "como é" "nata" (nada) e eh, como vemos nos exemplos transcritos:

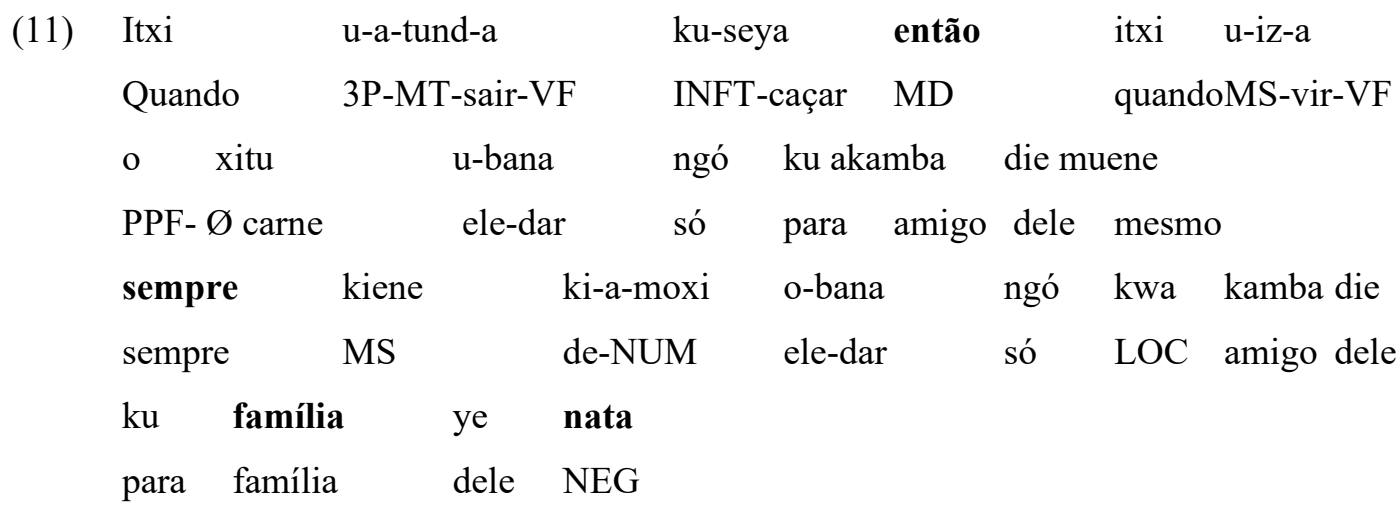

'Quando ele saiu para caça, então, quando ele vem, só dá a carne mesmo para seu amigo, sempre faz a mesma coisa, só dá a carne para o amigo, para a família não dá.'

O exemplo, apesar de longo, traz, além do MD 'então', os morfemas de conteúdo 'sempre' e 'família', e novamente o nata. Às vezes, 'então' é realizado como endã ou andã. Aqui, verificamos novamente o uso de advérbio em português 'sempre' preenchendo a função de morfema de conteúdo. No entanto, ngó, do quimbundo, não é substituído por 'só' do português como no exemplo (7) mencionado. Por outro lado, nata tem a função aqui de palavra de negação e ora é realizado como em português: 'nada', como será visto em exemplo adiante.

O marcador discursivo "como é", muito comum no português de Angola, ocorrendo também no corpus:
(12) Eji
u-a-nhi-kuat-es-a
sonhi,
komwe
disse
MS-MT- MO- envergonhar-APL-VF
Ø-vergonha MD
uosu
ngaha
esse todo
INTERJ

'Disse: me fizeste envergonhar, como é, vergonha tão grande assim nhahá!' 
O exemplo em (12) chama a atenção por ter sido transcrito por nosso colaborador nativo do quimbundo ter sugeridotranscrever 'como é' na forma komwe, como forma já nativizada do quimbundo. Surpreende que o mesmo colaborador, ao auxiliar na tradução do exemplo em (8), propôs novamente traduzir kuji como o MD 'como é'.

Em quimbundo, o marcador discursivo mais produtivo éo “ê", pronunciado /e:/, que pode receber diversas interpretações pragmáticas. A seguir, o MD foi traduzido por nosso intérprete de quimbundo como 'sim':
$(13)^{11}$ eh
histore
xi-avulu
ma-nona
u-avulu
MD história
10-muitas
6-provérbios
IS1-muitos
'Sim, são muitas histórias, muitos provérbios."

${ }^{11}$ Neste exemplo verifica-se uma discrepância na concordância de classe que seria esperado para ma-nona ma-vulu. Dado a ser investigado em novas sessões de eliciação.
Indaga-se se tal MD eh é próprio do quimbundo ou é proveniente do português, à semelhança do MD eh pa, discutido por Oliveira, Zanoli e Andrade (2018, p. 177). Trouxemos, assim, alguns exemplos de MDs no quimbundo por acreditarmos que uma análise contrastiva entre MDs em quimbundo e português do Libolo podem lançar luz ao real estatuto dessas palavras nos casos de empréstimo ou codeswitching quimbundo-português. Além disso, o uso de marcadores discursivos em quimbundo remete à questão da classificação dos morfemas no Modelo dos 4-M de Myers-Scotton (2002), como já mencionado, mas, como se observam nos exemplos em (12) e (13), fica a dúvida quanto à direcionalidade de interferência das línguas, se do português para o quimbundo ou vice-versa. As sugestões do nosso colaborador em 'quimbundizar' a grafia de 'como é' e a preferência por traduzir kuji como esse MD deixam como tarefa uma investigação mais detalhada sobre esse tópico de estudo para essas duas línguas.

\section{Consequências da classificação dos morfemas no Modelo dos 4-M para os dados do quimbundo: línguas em convergência?}

Foi mencionado que a classificação de morfemas no modelo dos 4-M é de interesse para se identificar, nas 
situações de contato, qual a LM e qual a LE. Não restam dúvidas de que, nos exemplos apresentados, o quimbundo é a LM e o português a LE. Não está muito clara, no entanto, a classificação, para línguas bantas, dos tipos de morfemas no modelo 4-M, principalmente os morfemas gramaticais tardios pontes e exteriores. Estes últimos são considerados como mais resistentes a serem transferidos, mesmo em situações de contato duradouras (MYERS-SCOTTON, 2008, p. 21). Acreditamos que este seja o caso das variedades de português e quimbundo do Libolo, como atestado nos exemplos de empréstimos em gramáticas de cinquenta anos atrás.

Um exame detalhado da interação entre os diferentes morfemas do modelo dos 4-M pode indicar se as duas línguas estariam realmente em uma situação de convergência (em que os morfemas de superfície são de uma língua e parte da estrutura abstrata é de outra nos termos de MyersScotton). No entanto, é necessário que se olhe para o contexto sociolinguístico do Libolo para que se corrobore não apenas a situação de convergência como também a de atrito de língua.

O modelo dos 4-M pode auxiliar na constatação de que as duas línguas estão em contato, apesar das dúvidas que ainda pairam sobre o caso de alguns exemplos:

$\begin{array}{lllllll}\text { (14) nada! } & \text { ng-a-kuka } & \text { ni } & \text { ene } & \text { a-kuku } & \text { etu } & \text { ka-tu- } \\ \text { nada } & \text { MS-MT-velho } & \text { COM } & 3 \mathrm{pl} & \text { IS-avós } & 1 \mathrm{pl} & \text { NEG- } \\ \text { mu } & \text { xikola } & & & & & \\ 16 & \text { escola } & & & & & \end{array}$

'Nada! Estou velha, e com eles, nossos avós, não tínhamos ido à escola.'

Pelos poucos exemplos do uso de nada/nata, questionamos seus usos ora como marcador negativo ora como MD. De qualquer modo, o que os dados até o momento podem sugerir é de que o contato do quimbundo com o português é de longa data, como já observado com o caso de empréstimos registrados em gramáticas de meados do século XX e mesmo anteriores (CHATELAIN, 1988/1989; MAIA, 1964).

Por outro lado, os diversos estudos conduzidos pelos pesquisadores da equipe do português L1 e L2 do Libolo 
(FIGUEIREDO; OLIVEIRA, 2013; FIGUEIREDO, OLIVEIRA; JORGE, 2016) apontam não apenas para uma influência substratista do quimbundo para o português do Libolo, mas para uma possível convergência.

Para deixar mais ilustrativo, vale apresentar aqui um exemplo curioso no qual foi verificado o uso do pré-prefixo do quimbundo 'o', morfema utilizado para marcar nominais com valor de definitude, portanto, um morfema gramatical precoce, em uma palavra do português considerada morfema de conteúdo, 'depois':

(15)

$\begin{array}{llllll}\text { u-andal-a } & \text { ku-ambat-a } & \text { ma-nono } & \text { ina } \\ \text { 3sg-querer-VF } & \text { 15-levar-VF } & \text { 6-anedota } & \text { assim } & \\ \text { u-andal-a } & \text { ku-ambat-a } & \text { umu umu } & \text { mu } & \text { aparelo } \\ \text { 3sg-querer-vf } & \text { 15-levar-VF } & \text { aqui aqui } & 16 & \text { aparelho } \\ \text { ma-makini-i } & \text { o } & \text { depoxi } & \text { yo-a-ka-conda-el-a } & \text { oko } \\ \text { 6-máquina-esta } & \text { PPF } & \text { depois } & \text { ?-MT-MO-contar-APL-VF lá } \\ \text { na } & \text { oku } & \text { a-tund-u } & & & \\ \text { COM } & \text { LOC } & \text { MS-sair-VF } & & & \end{array}$

'Quer levar as anedotas assim, quer levar aqui, aqui, no aparelho aqui, (na) máquina, e depois estará contando de onde lá ali saiu.'

Novamente, é possível identificar empréstimos com e sem marcas de classes nominais. 'Aparelho' aparece marcado com a classe locativa 16, mas 'máquina' foi inserido na classe 6 por semelhança com a primeira sílaba da palavra, como já sabido para a acomodação de empréstimos (MOUS, 2019). O uso do pré-prefixo antes de 'depois' é no mínimo curioso por demonstrar uma flutuação na classificação categorial das palavras emprestadas e a busca por um critério mais firme para a identificação dos diferentes tipos de morfemas no modelo 4-M, objetivo perseguido por Myers-Scotton e Jake (2019) em seu trabalho recente sobre o referido modelo ao proporem a Hipótese da Escolha Variável. 


\section{Considerações finais}

Atentar para dados de empréstimos e codeswitching entre línguas em contato requer uma postura teórica condizente com o objeto de investigação. Os dados do quimbundo e do português do Libolo discutidos neste trabalho com base nos modelos teóricos de Myers-Scotton (2002) apontam para uma possível situação de convergência e atrito entre línguas.

A análise dos dados demonstra o interesse do modelo dos 4-M para o estudo de codeswitching e empréstimos. A Hipótese de Escolha Variável (MYERS-SCOTTON; JAKE, 2016) permitirá explicar a incorporação diferenciada de morfemas gramaticais, só verificados com os morfemas gramaticais precoces, conceptualmente ativados, como os morfemas de conteúdo. Em (14) ng-a-kuka, o morfema de conteúdo do quimbundo $k u k u$ 'avô, avó, velho, velha' recebe a concordância de gênero do português, o morfema 'a', um morfema gramatical precoce conceptualmente ativado. Tanto o morfema de gênero do português quanto o de conteúdo são conceptualmente ativados e, por isso, foram escolhidos, conforme a hipótese da escolha variável de MS, que se baseia no traço [+conceptualmente ativado].

\section{REFERÊNCIAS}

ANGENOT, Jean-Pierre; MFUWA, Ndonga; RIBEIRO, Michela Araújo. As classes nominais do kibala-ngoya, um falar bantu de Angola não documentado, na intersecção dos grupos kimbundu [H20] e umbundo [R10]. Papia v. 21, n. 2, p. 253-266, 2011.

ANGENOT, Jean-Pierre; ANGENOT, Geralda de L.; HUTAMUKANA, Daniel Mutombo. Comparision between the IpalaNgoya, Kimbundu and Umbundu tone-cases systems. Revista Lingua Viva, v. 3, n. 1, p. 1-28, mar./ago. 2013.

ARSÉRNIO, Manuel João; SEBASTIÃO, Judite João Conde; ADÃO, António. Manual de Alfabetização em Kimbundu. Luanda: África Internacional, 2012. 
BEYER, Klaus. Language contact. In: VOSSEN, Rainer; DIMMENDAAL, Gerrit. (org.). The Oxford Handbook of African Languages. Oxford: Oxford University Press, 2020.

CÁTEDRA do Português. [S. 1.], c2008. Disponível em: https:// catedraportugues.uem.mz/?_target__=bibli\&bib=1. Acesso em: 28 set. 2020.

CHATELAIN, Héli. Kimbundu grammar. Grammatica elementar do kimbundu ou língua de Angola. Genève: Type de Charles Schuchardt, 1888-1889.

COETSEM, Frans van. A General and Unified Theory of the Transmission Process in Language Contact. Heidelberg: Universitätsverlag, C. Winter, 2000.

FIGUEIREDO, Carlos Felipe Guimarães; OLIVEIRA, Márcia Santos Duarte de (org.). Linguística, História, Antropologia e Ensino no Kwanza Sul, Angola. Lisboa: Chiado Editora, 2016. v. 1.

FIGUEIREDO, Carlos Felipe Guimarães. Retratos do Libolo. Lisboa: Chiado Editora, 2016. Vol. 2.

FIGUEIREDO, Carlos Filipe G., OLIVEIRA, Márcia Santos Duarte de Oliveira; JORGE, Lurdes Teresa Lopes Jorge. Clítico argumental "lhe" no português do Libolo: estrutura formal e caso (abstrato). In: FIGUEIREDO, Carlos Felipe Guimarães; OLIVEIRA, Márcia Santos Duarte de. (org.). Linguística, História, Antropologia e Ensino no Kwanza Sul, Angola. Lisboa: Chiado Editora, 2016. v. 1.

FIGUEIREDO, Carlos; OLIVEIRA, Márcia Santos Duarte de. Português do Libolo, Angola, e português afro-indígena de Jurussaca, Brasil: cotejando os sistemas de pronominalização. Papia, São Paulo, v. 23, n. 2, p. 105-185, 2013.

FIGUEIREDO, Carlos Filipe G. Aspectos histórico-culturais e sociolinguísticos do Libolo: aproximações com o Brasil. In: ARAÚJO, Gabriel Antunes de; OLIVEIRA, Márcia Santos Duarte de (org.). O português na África Atlântica: Angola, Cabo Verde, Guiné-Bissau, São Tomé e Príncipe. 2 ed., São Paulo: FFLCH/USP, 2019. 
HAMMARSTRÖM, Harald. An inventory of Bantu languages. In: VELDE, Mark van de; BOSTOEN, Koen; NURSE, Derek; PHILIPSON, Gérard (org.). The Bantu Languages. 2 ed. Londres: Routledge, 2019.

HUTH, Karin. Untersuchungen zum nominalklassensystem des kimbundu (vr Angola) unter Berücksishtigung der entwicklungstendenzen siener urbanen varianten. (Estudo do sistema de classes nominais do Kimbundu tendo em conta as tendências do desenvolvimento de sua variedade urbana) Tese (Doutorado em Estudos Africanos). Karl-Marx-Universität, Leipzig, Alemanha, 1984.

IDENTIDÁFRICA. [S.1.], c2010. Disponível em: https:// rmirandas.wixsite.com/identidafrica/coleomanuaisdealfabet izao?lang=en. Acesso em: 29 set. 2020.

LEVELT, Willem J. M. Speaking: from intention to articulation. Cambridge, MA: MIT Press, 1989.

LÓPEZ, Laura Álvares; GONÇALVES, Perpétua; AVELAR, Juanito Ornelas de. (org.). The Portuguese Continuum in Africa and Brazil. Amsterdam: John Benjamins, 2018.

MAIA, Antonio da Silva. Dicionário Complementar PortuguêsKimbundu-Kikongo: Linguas Nativas do Centro e Norte de Angola. Luanda: Cooperação Portuguesa, 1961.

MATRAS, Yaron. Language Contact. Cambridge: Cambridge University Press, 2009.

MOUS, Maarten. Language contact. In: VELDE, Mark van de; BOSTOEN, Koen; NURSE, Derek; PHILIPSON, Gérard (org.). The Bantu Languages. 2 ed. Londres: Routledge, 2019.

MUFWENE, Salikoko. Contact Languages in the Bantu Area. In: NURSE, Derek; PHILIPPSON, Gérard (org.) The Bantu Languages, 1 edição. Londres: Routledge, 2003.

MYERS-SCOTTON, Carol. Language Contact: bilingual encounters and grammatical outcomes. Oxford: Oxford University Press, 2002. 
Language contact: why outsider system morphemes resist transfer. Journal of Language Contact - THEMA 2, 2008.

MYERS-SCOTTON, Carol; JAKE, Janice. Revisiting the 4-M model: Codeswitching and morpheme election at the abstract level. International Journal of Bilingualism, v. 21, n. 3, p. 340-366, 2016.

OLIVEIRA, Márcia Santos Duarte de; ZANOLI, Maria de Lurdes; ANDRADE, Giovana Merighi. Marcadores discursivos no português falado em Angola, subvariedade Libolo: um estudo inicial de base prosódico-pragmática. Filol. Linguist. Port., v. 20, n. Especial, p. 159-186, 2018.

PEDRO, José Domingos. Étude grammaticale du kimbundu (Angola). Thése (Doctorat en Linguistique). Universidade René Descartes, Paris, 1993.

PETTER, Margarida. Variedades lingüísticas em contato: português angolano, português brasileiro e português moçambicano. Tese (Livre-Docência em Linguística Africana). Universidade de São Paulo, São Paulo, 2008.

Introdução. In: PETTER, Margarida (org.). Introdução à Linguística Africana. São Paulo: Contexto, 2015.

VELDE, Mark van de; BOSTOEN, Koen; NURSE, Derek; PHILIPSON, Gérard (org.). The Bantu Languages. 2 ed. Londres: Routledge, 2019.

WINFORD, Donald. On the unity of contact phenomena: the case for imposition. In: FÉRAL, Carole de. In and out of Africa: Languages in question - In honor of Robert Nicolaï. Louvain: Peeters, 2013. v. 1. (Language contact and Epistemological Issues).

XAVIER, Francisco da Silva. Fonologia Segmental e SupraSegmental do Quimbundo - Variedades de Luanda, Bengo, Quanza Norte e Malange. Tese (Doutorado Linguística), Universidade de São Paulo, São Paulo, 2010. 


\section{Abstract \\ Kimbundu and Portuguese of Libolo (Angola): Languages in Contact}

Portuguese sub-variety spoken in Angola in the municipality of Libolo, province of Kwanza Sul, is a second language for a good portion of the population of that municipality. This article presents results from investigations within an interinstitutional and international project: the Libolo Project, specifically focusing on the contact of the kimbundu in its variety known as ngoya or kibala (H23) with Libolo's Portuguese. The theoretical models developed by Myers-Scotton (2002) and Myers-Scotton and Jake (2016) are used for data analysis, notably the 4-M model as a way of verifying lexical preferences in the codeswitching and loan phenomena between the two languages in focus. Preliminary data from the corpus of Projeto Libolo are presented, examined from the perspective of the theoretical models in question in this work. It also seeks to understand the type of relation of Kimbundu and Portuguese as languages in contact and how that relation may contribute to the discussion of an Afro-Brazilian Portuguese continuum (PETTER, 2008).

Keywords: Kimbundu. Portuguese. Languages in contact. Libolo.

\section{Declaração de financiamento}

O primeiro autor agradece à Fundação de Amparo à Pesquisa do Estado de São Paulo (FAPESP) pela bolsa de pós-doutorado (Processo 13/20567-5) que financiou a pesquisa deste artigo decorrente do projeto “O português e o quimbundo(H20) do Libolo, Kwanza Sul, Angola - avaliando modelos teórico de línguas em contato" vinculado ao Projeto Temático "A Língua Portuguesa no Tempo e no Espaço: contato linguístico, gramáticas em competição e mudança paramétrica" (Processo 12/06078-9). 
Paulo Jeferson Pilar Araújo é Doutor em Linguística pela Universidade de São PauloUSP e em Linguística Africana pela Bayreuth International Graduate School of African Studies-BIGSAS em Programa de duplo doutorado entre a USP e a Universidade de Bayreuth, Alemanha. Orienta pesquisas nas áreas de linguística das línguas de sinais, linguística africana e do contato no Programa de Pós-graduação em Letras-PPGL da Universidade Federal de Roraima-UFRR. Professor adjunto do Curso de Letras Libras Bacharelado da UFRR. Líder do Laboratório de Pesquisas em Línguas Orais e de Sinais-LaPLOS (CNPq) e pesquisador da Cátedra Unesco em "Políticas Linguísticas para o Multilinguismo" (UCLPM/UFSC).

Margarida Petter é professora livre-docente do Departamento de Linguística da Universidade de São Paulo, onde também se doutorou. Realizou estágios de pós-doutorado no laboratório LLACAN (Langage, Langues et Cultures d'Afrique Noire) do CNRS-Paris e na Universidade de Bayreuth, na Alemanha. Desenvolve, atualmente, pesquisas sobre as línguas africanas do grupo banto e o contato dessas línguas com o português brasileiro. Orienta projetos de mestrado e doutorado e supervisiona estágios de pós-doutorado no Programa de Pós-Graduação em Linguística da USP. 